\title{
Rock mass property evaluation based on the borehole wall images taken by using an ultrasonic scanner (USS)
}

\author{
Yasunori Ootsuka ${ }^{1}$, Takanori Ishikawa ${ }^{1}$, *Katsuhiro Tajima ${ }^{1}$, Testu Wada ${ }^{2}$, \\ Ömer Aydan ${ }^{3}$, Naohiko Tokashiki ${ }^{3}$, Tshinori Sato ${ }^{4}$, and Kazuhei Aoyagi ${ }^{4}$ \\ ${ }^{1}$ Earth Scanning Association, Yokohama, Kanagawa, Japan \\ ${ }^{2}$ RaaX Co., Ltd., Sapporo, Hokkaido, Japan \\ ${ }^{3}$ University of Ryukyu, Okinawa, Japan \\ ${ }^{4}$ Japan Atomic Energy Agency, Horonobe, Hokkaido, Japan \\ *Corresponding author: k.tajima@esa.gr.jp
}

\begin{abstract}
Discontinuities, such as faults and fractures exist even in Neogene soft sedimentary rocks. These discontinuities play an important role for determination of physical, mechanical and hydraulic properties of rock mass. For geological disposal of high-level radioactive waste, these data should be obtained for designs of the layout of repository, engineered barrier system and safety assessment. Rock mass properties are important information for quantitative rock mass classification as well as for design and construction of underground facilities and assessment of safe waste disposal. Ultrasonic wave reflection intensity of the wall of the borehole drilled from bottom of East Access Shaft in Horonobe Underground Research Laboratory Center, Hokkaido, Japan, was obtained by using the ultrasonic scanner (USS). In this paper, we compared results of USS observation with core logging data including the core observation, the optical digital scanner (ODS) observation, and result of Needle Penetration Index (NPI) tests. These results indicated that ultrasonic wave reflection intensity had a good correlation with other observation results, and USS observation and NPI test are useful techniques for the determination of the detailed rock mass classification.
\end{abstract}

Keywords: Borehole wall image, Ultrasonic scanner, Optical digital scanner, Needle penetration index, Rock mass properties

Paper Received: 31 Jan 2018

Paper Accepted: 16 March 2018

\section{INTRODUCTION}

Horonobe Underground Research Laboratory Center conducts the research and development on the geological disposals of high-level radioactive waste and geoscientific research to verify the technical reliability of the geological disposals through the testing and research conducted in actual deep geological environments. The geology of this research Laboratory Center consists of Neogene mudstones. The field experiments were conducted in the Wakkanai Formation of siliceous mudstone (Fig. 1).

For geological disposals of high-level radioactive wastes, the in-situ data on rock mass properties should be obtained for design of the engineered barrier system and the safety assessment. Discontinuities, such as faults and fractures exist even in Neogene soft sedimentary rocks. These discontinuities play an important role for the determination of physical, mechanical and hydraulic properties of rock mass.

As mentioned above, rock mass properties are important information for quantitative rock mass classification for the design and construction of underground facilities and safety assessment of waste disposal. Various field test methods in addition to boring core are being studied.

\section{METHODS}

The purpose of the field tests is to evaluate and quantify discontinuities in the soft sedimentary rock and to establish appropriate evaluation methods. Artificial cracks were generated in the acquired boring core as a result of drilling at the large depth and new exploration methods were required to distinguish natural geological cracks from artificial ones. The targeted rock is siliceous mudstone called the Wakkanai Formation. It is distributed to a depth of more than about $300 \mathrm{~m}$. We utilized the Ultrasonic Image Scanner (USS) and Needle Penetration Index (NPI) test, and compared the numerical data of USS with the data of NPI with the core logging data.

\section{Outline of drilling}

A drilling was conducted from the bottom of the East Access Shaft (Fig. 2).

Depth: -380 -499.7 m $(\mathrm{L}=119.7 \mathrm{~m})$ 


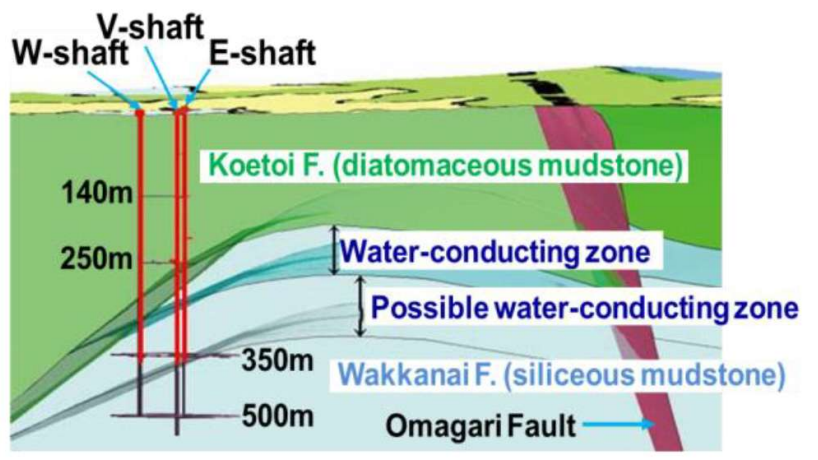

Pliocene-Pleistocene

Sarabetsu Formation

Yuchi Formation

Miocene-Pliocene

Koetoi Formation

Miocene

Wakkanai Formation

Fig. 1: Geological Model around Horonobe

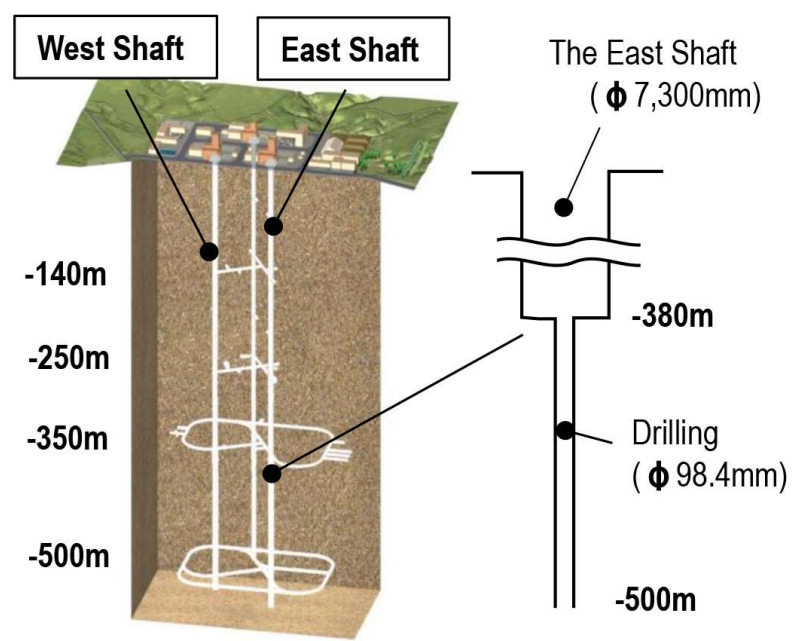

Fig. 2: Outline of Drilling

Drilling diameter: $98.4 \mathrm{~mm}$

Core sample diameter: $63.5 \mathrm{~mm}$

\section{Field tests}

The four field tests, which were conducted at a depth of $-460 \mathrm{~m}$ to $-499.7 \mathrm{~m}(\mathrm{~L}=39.7 \mathrm{~m})$, are (i) observation of drilling core, (ii) NPI test, (iii) optical borehole camera, and (iv) ultrasonic borehole camera.

\section{Needle Penetration Index test}

The needle penetration test is the testing method which a needle is inserted into rocks to observe the penetration depth

$$
\operatorname{NPI}(N / \delta)=\frac{\text { Penetration load }(\mathrm{N})}{\text { Needle penetration length }(\mathrm{mm})}
$$

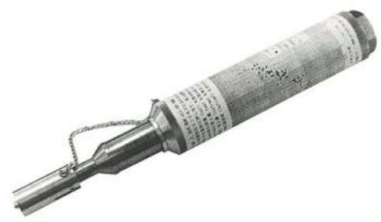

Fig. 3: Needle penetration tester

and load. The Needle Penetration Index is obtained from the relation between the two parameters. This test method is mainly applicable for soft rock. The NPI is calculated by reading the needle penetration depth $(\mathrm{mm})$ when the penetration load $(\mathrm{N})$ reaches $100 \mathrm{~N}$, or the penetration load when the needle penetration amount is $10 \mathrm{~mm}$ (Aydan et al. 2014; Ulusay et al. 2014). It was utilized for the drilling core at every $20 \mathrm{~cm}$ interval and calculated NPI from penetration load and needle penetration depth by the following formula (Fig. 3).

\section{Optical borehole camera (Kawakami et al., 2014)}

In the field test, two types of borehole image scanners were used. One is an optical digital scanner (ODS), and the other one is an ultrasonic scanner (USS). As shown in the photo, this system consists of a probe, controller, depth encoder, remote control winch and a note-book pc. The feature of this system is to get both data easily by exchanging a probe and a controller (Fig. 4). The ODS is an optical camera to take borehole wall images from a constant azimuth. Fig. 5 is a conceptual view of how ODS acquires data.

\section{Ultrasonic borehole camera (Kawakami et al., 2014)}

On the other hand, the USS is a system, which revolves an ultrasonic wave oscillator and receiver in a spiral manner to continuously measure the ultrasonic wave reflection intensity of the borehole wall and obtains borehole wall images by

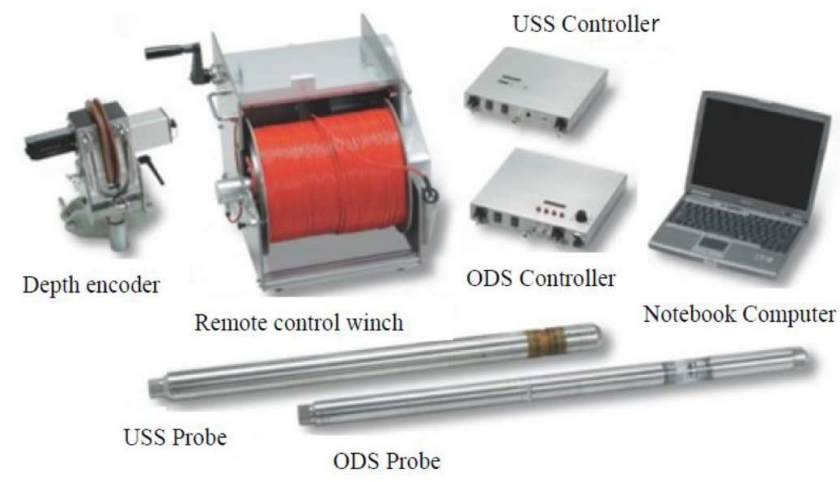

Fig. 4: Two types of borehole image scanners 

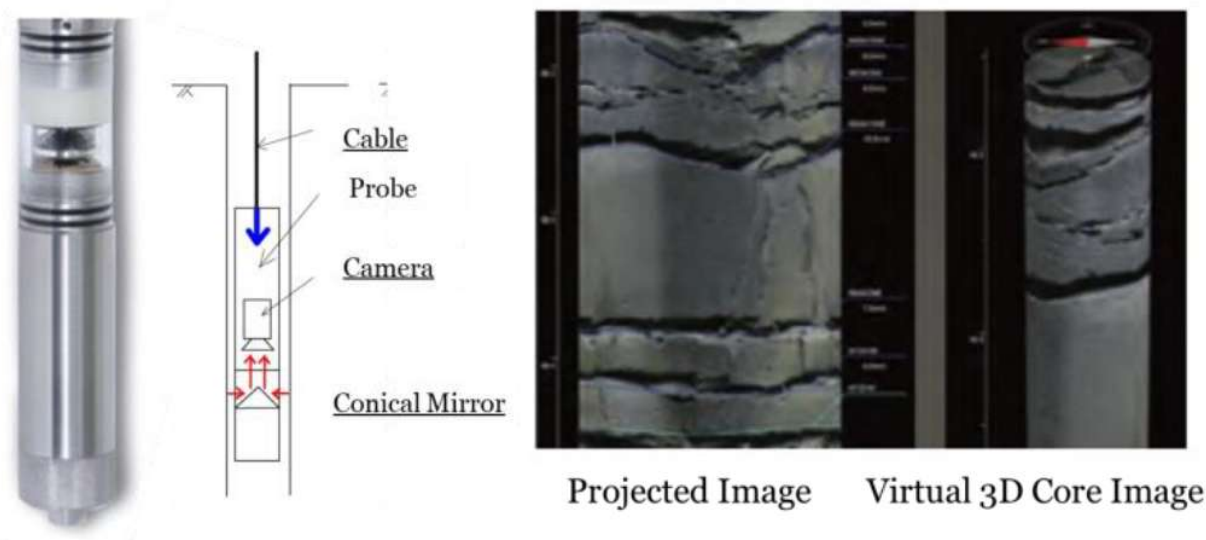

Fig. 5: Conceptual View of How ODS Collects Data
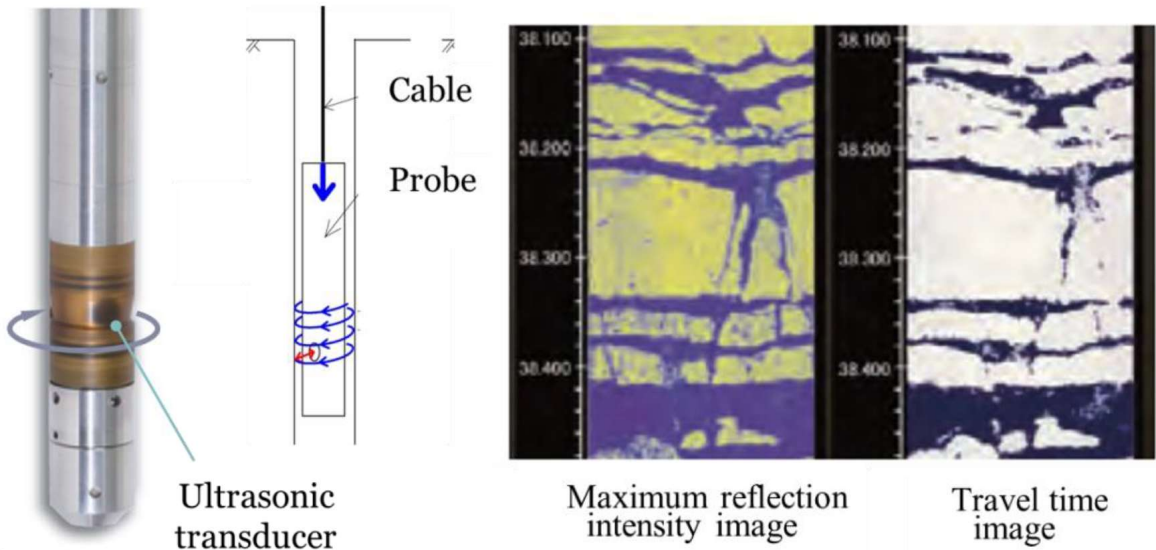

USS Probe

Fig. 6: Conceptual View of How USS Collects Data

converting the intensity into 256-tone color density (Fig. 6), is a conceptual view of how ODS acquire data.

\section{RESULTS}

\section{Observation of Drilling core}

We divided the natural geological cracks into three groups as shown below. There were many artificial cracks by core disking in the horizontal direction due to large depth drilling. Particularly in at the place with a high dip geological crack, the core became fine debris due to artificial horizontal cracks as shown in Fig. 7. It was necessary to know the real geological status in the borehole.

\section{Evaluation of ultrasonic reflection intensity data of USS}

We calculated two reflection strengths of USS by Ave and Dev, sorted them as reflection intensity characteristic values, and used them for analysis (Tokashiki et al., 2008; Yasutomi et al., 2015).
The average reflection intensity (Ave) and the standard deviation (Dev) from the average value were calculated from the following formula shown in Fig. 8, using the reflection

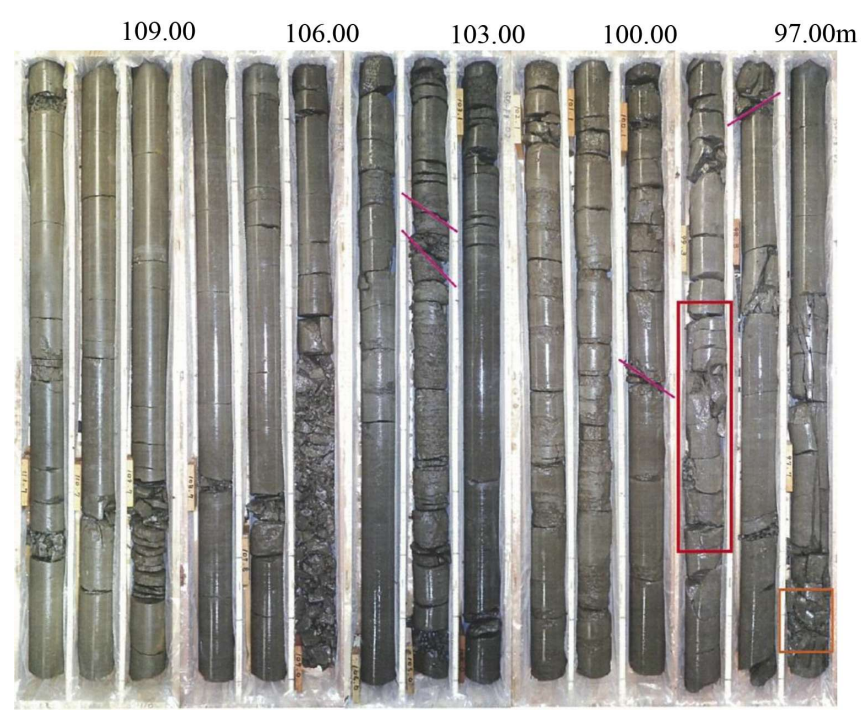

Fig. 7: Picture of drilling core (97-112 m) 


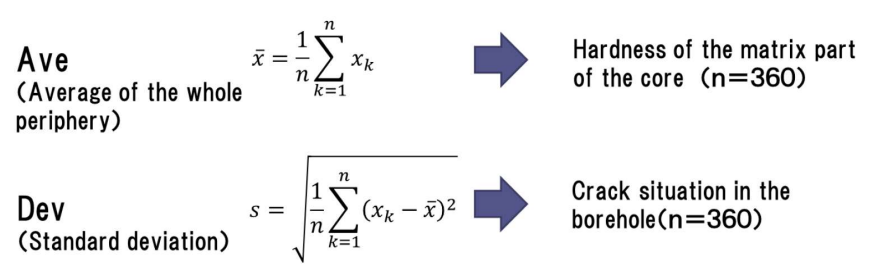

Fig. 8: How to calculate Ave and Dev from USS data

intensity data of the whole periphery at every $1 \mathrm{~mm}$ interval. Ave shows the hardness of the matrix part of the core while Dev shows the crack situation in the borehole basically.

\section{Comparison with Needle Penetration Index Test}

We created the graph of the values obtained by averaging the whole periphery of the reflection intensity values of the ultrasonic borehole camera (USS) and the NPI obtained from the needle penetration index test result of the core shown in Fig. 9. We found that there were some sections (A zone) where there was a big change in the average NPI was small, and we also found Ave value is smaller in A zone.

\section{Evaluation using both Ave and Dev values}

By using calculated Ave and Dev, the characteristic parts were classified into four zones A, B, C, D as shown in Fig. 10 to 12 and summarized them in Table 1 . The image of USS

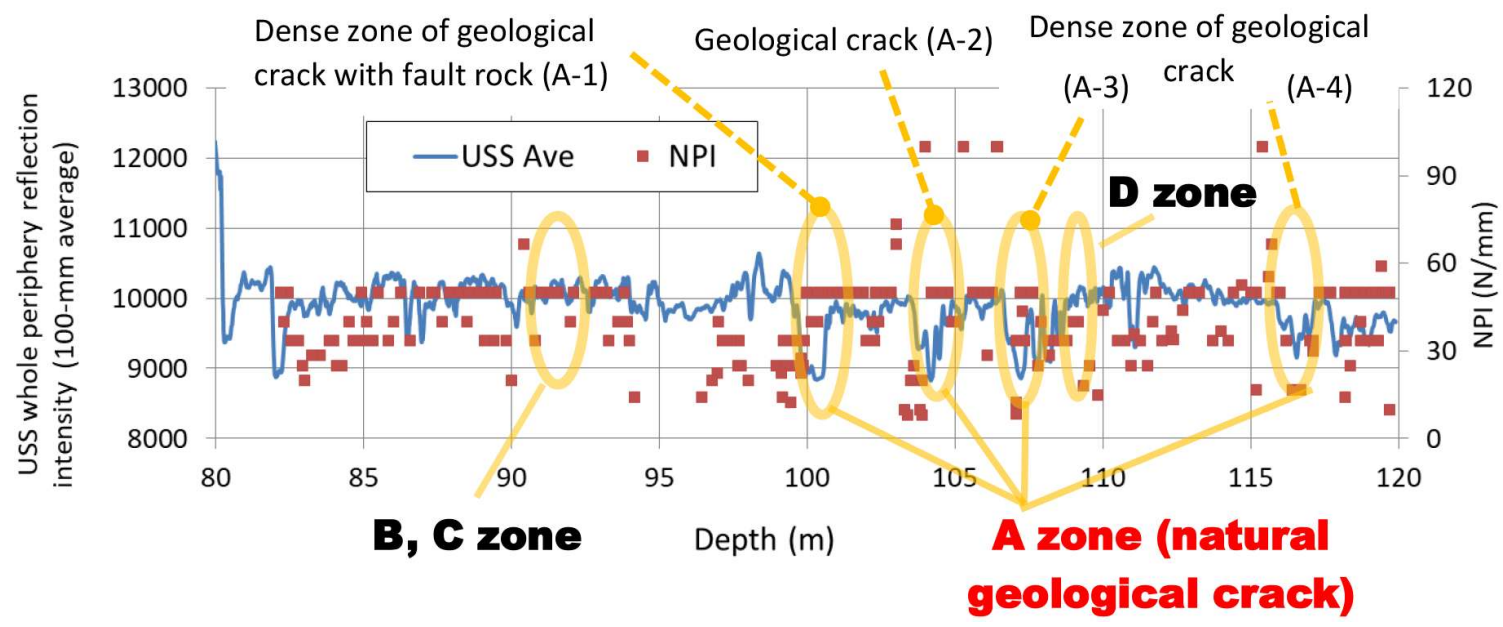

Fig. 9: Depth Distribution Chart of Ave and NPI

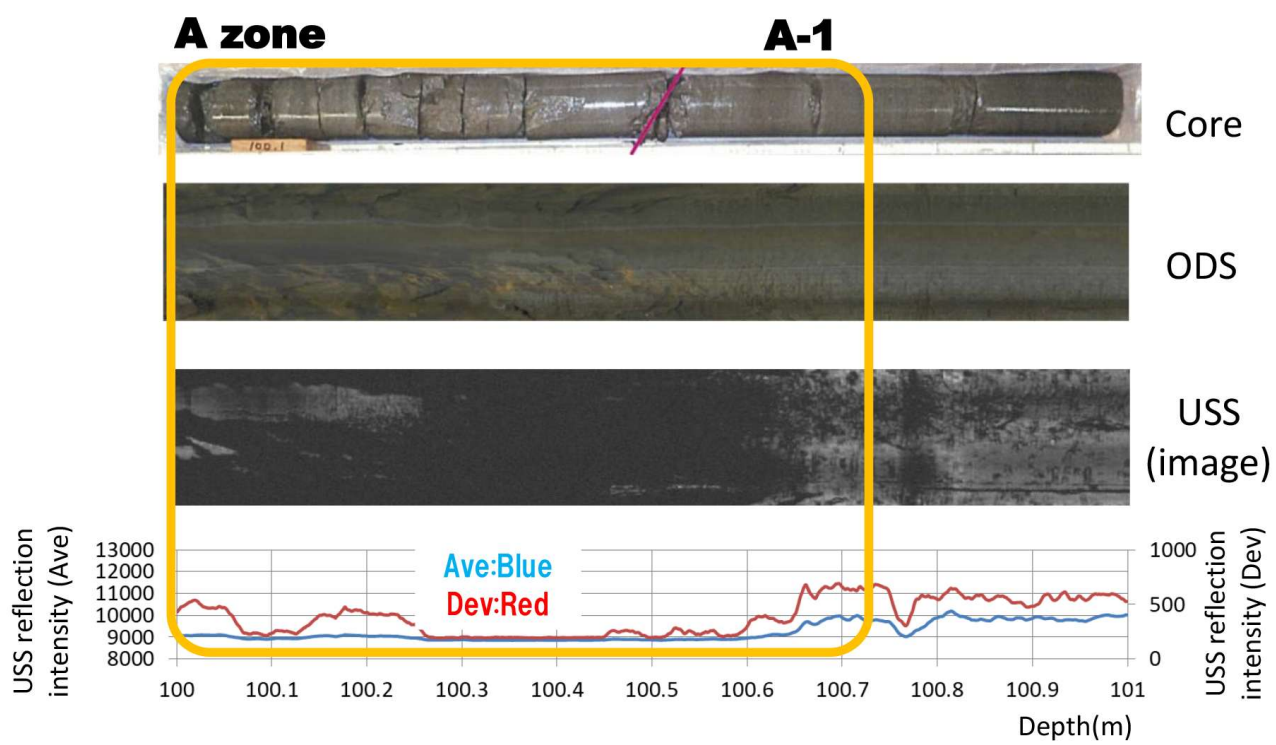

Dev : Low, Ave : Low, Span : Long $\rightarrow$ Dense zone of geological cracks

Fig. 10: Depth Distribution Chart of Ave and Dev data and Borehole Image (A zone) 


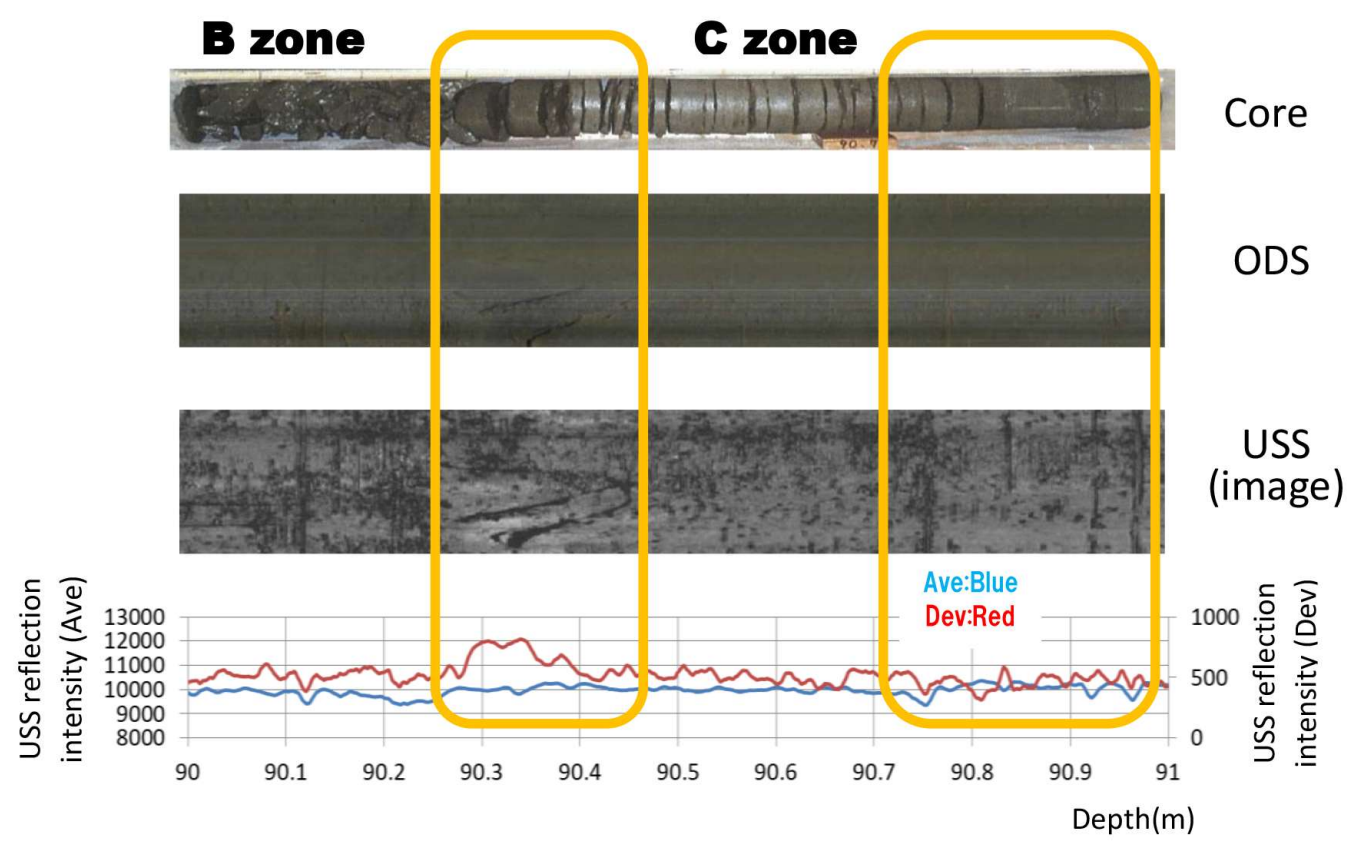

B Dev : High, Ave : No Change, Span : Short $\rightarrow$ Single geological crack

C Dev : Low(Spike), Ave : Low (Spike), Span : Very Short $\rightarrow$ Artificial crack

Fig. 11: Depth Distribution Chart of Ave and Dev data and Borehole Image (B and C zones)

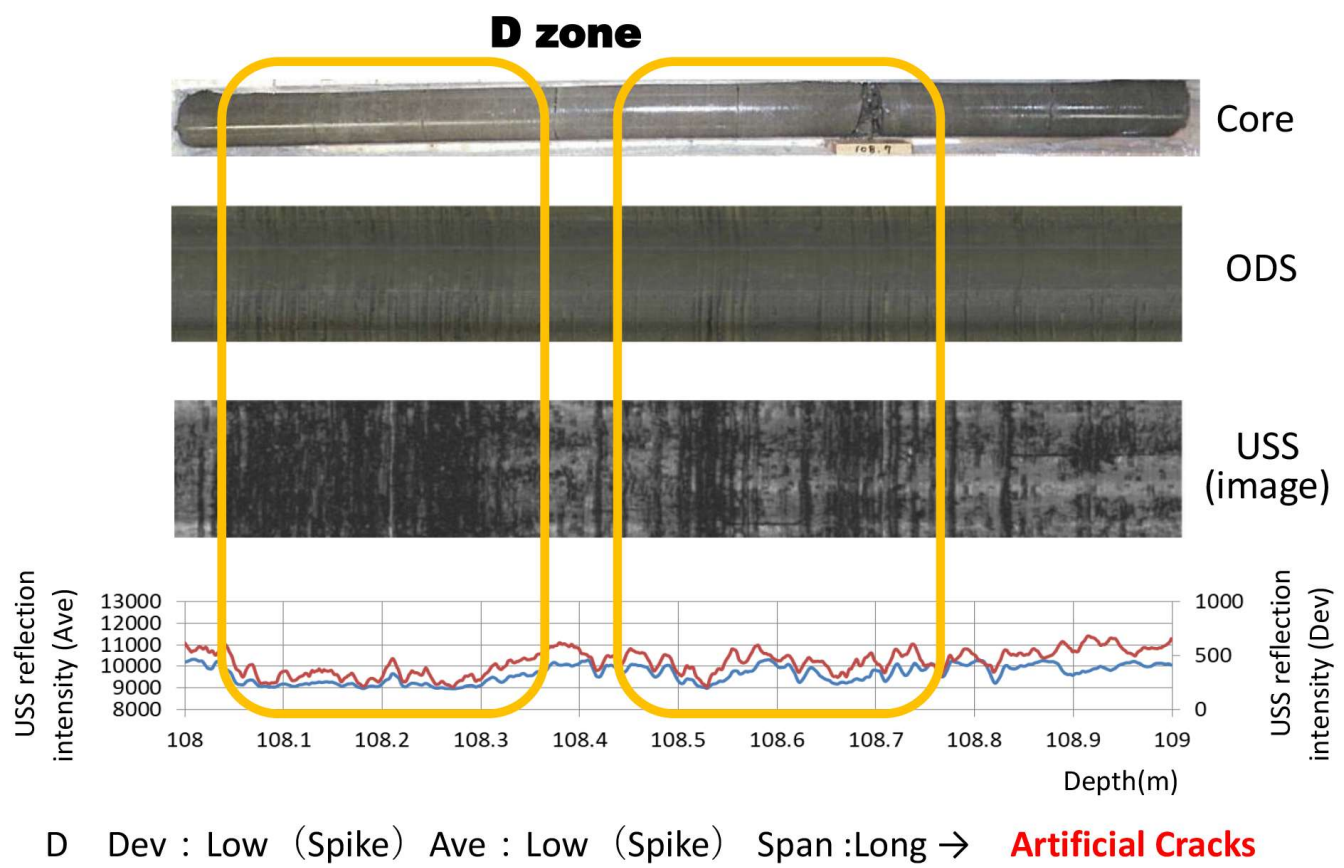

Fig. 12: Depth Distribution Chart of Ave and Dev data and Borehole Image (D zone) 
Table 1: Rock mass condition estimated from reflection intensity data of USS

\begin{tabular}{lllllll}
\hline Deviation (Dev) & Average (Ave) & Zone & Length of Span & Borehole wall condition & Rock mass condition & NPI \\
\hline High $\sim$ Low & Low & A & Short $\sim$ Long & Natural crack & Single crack $\sim$ Crack zone & Smaller \\
High & No change & B & Short & Natural crack & Single crack & No change \\
Low (Spike) & Low (Spike) & C & Short & Artificial crack & Single crack & No change \\
Low (Spike) & Low (Spike) & D & Long & Artificial crack & Multiple crack & Smaller \\
\hline
\end{tabular}

clearly displayed the status of the borehole wall. Especially in the USS image of B zone, it is possible to clearly confirm a single geological crack not shown by ODS (Fig. 11). In C zone and D zone, we can confirm disorders of the borehole wall such as a bit scratch (Figs. 11 and 12). These figures suggested the ultrasonic waves reflected from the borehole wall indicate the fine irregularities of the borehole wall more clearly, that is a major feature of USS. From the analysis of USS reflection intensity data, we listed the whole periphery average (Ave) of the reflection intensity and the standard deviation (Dev) as given in Table 1. The tendency of the ultrasonic reflection intensity which changes with these graphs shows the state itself of the borehole wall of the rock mass.

\section{CONCLUSIONS}

The conclusions from this study are as follow:

1. In rock mass property evaluation at a large depth, it is necessary to distinguish between natural geological cracks and artificial cracks.

2. Optical digital scanner (ODS) is an effective tool for such a purpose. However, it is necessary to clean the water in the borehole particularly for mudstones.

3. Ultrasonic scanner (USS) is also very effective to get a borehole image and to know the real geological crack situation in the borehole particularly in mudstone.

4. Proposed Ave and Dev values, which are derived from USS, represent the situation of the real geological cracks in the borehole and are very useful as auxiliary data for core observation.

\section{REFERENCES}

Aydan. Ö., Sato, A., and Yagi, M., 2014, The inference of geomechanical properties of soft rocks and their degradation from needle penetration tests. Rock Mech Rock Eng., vol. 47, pp.1867-1890.

Kawakami, A., Yasutomi, H., Murata, A., Nakahara, T., Hiraki, H., Moriguchi, Y., Ootsuka, Y., and Tajima, K., 2014, Comparison of borehole scanning systems, Optical digital scanner (ODS) and ultrasonic scanner (USS), Proceedings of 8th Asian Rock Mechanics Symposium, ISRM, pp. 2224-2232.

Tokashiki, N. and Aydan, Ö., 2008, Evaluation of Deformability Properties of Rocks with Overlapping Inclusions by Different Averaging Methods. The 12th International Conference of International Association for Computer Methods and Advances in Geomechanics (IACMAG), Goa, India, pp. 797-804.

Ulusay, R., Aydan Ö., Erguler, Z.A., Ngan-Tillard, D.J.M., Seiki, T., Verwaal, W., Sasaki, Y., and Sato, A., 2014, ISRM Suggested Method for the needle penetration test. Rock Mechanics and Rock Eng., vol. 47, pp.1073-1085.

Yasutomi, H., Moriguchi, Y., Aydan, Ö., Tokashiki, N., Hachino, Y., Ishikawa, T., Nakahara, T., Hiraki, N., Yamada, N., Kawakami, T., Murata, A., Toya, N., Miyazawa, T., and Tajima, K., 2015, Estimation of Boring Pit Wall Strength Using Ultrasonic Wave Reflection Intensity, Japan Society of Engineering Geology Workshop, pp.129-130. 